\title{
A New Dynamic Analysis Method for Hang's Mudding-Off Technique based on Circulation Loss in Return
}

\author{
Hong Liu ${ }^{1,2,4,5}$, Pu Liu ${ }^{3, *}$, Feng-ling Xu ${ }^{3}$, Qiao Chen ${ }^{4,5}$, Hong-ling $\mathrm{Zhu}^{4}$, and De-gui Su ${ }^{1,2}$ \\ ${ }^{1}$ National Joint Local Engineering Research Center for Shale Gas Exploration and Development, Chongqing Institute of Geology and \\ Mineral Resources, Chongqing 400042, China; \\ ${ }^{2}$ Key Laboratory of Shale Gas Exploration, Ministry of Natural Resources, Chongqing Institute of Geology and Mineral Resources, \\ Chongqing 400042, China; \\ ${ }^{3}$ Chongqing Fuling Shale Gas Environmental Protection R \& D and Technical Service Center, Chongqing 408000, China; \\ ${ }^{4}$ Chongqing Institute of Green and Intelligent Technology, Chinese Academy of Sciences, Chongqing 400714, China. \\ ${ }^{5}$ Key Laboratory of Mine Geological Hazards Mechanism and Control Xi'an, Shaanxi 710054, China.
}

\begin{abstract}
Hang's mudding-off technique is a well control measure used to maintain the dynamic balance of the pressure inside a well and thus ensure safe operation when there is circulation loss in the return. Given the lack of a dynamic analysis method that reflects the principles of annulus liquid level changes in a well shaft, there has been no analytical basis for applying Hang's mudding-off technique in practice, and as a result, the technique is typically applied as a "blind Hang". In this study, a dynamic analysis method was employed to model well shaft leakage loss, based on actual engineering conditions under which Hang's mudding-off technique is used, and models were developed for the effective height of the well shaft annulus liquid level in Hang's mudding-off technique and for a safe operation time after the application of the technique. The calculation of variations in the cross-sectional area of the annulus was also addressed. The reliability of the proposed models was evaluated using calculation examples. The error in the calculated effective liquid level height was $1.22 \%$ when dynamic leakage loss was considered, and the error in the safe operation time calculation was $3.58 \%$. These results illustrate the accuracy of the models. The analysis method proposed in this paper can be used to solve problems related to calculation of the engineering parameters involved in Hang's mudding-off technique and averting the risks of well control safety under conditions of circulation loss in the return, thereby optimising Hang's mudding-off technique and reducing project costs.
\end{abstract}

\section{Introduction}

Loss of circulation often occurs when drilling oil and gas wells and can lead to well control safety risks in the most serious cases (Lin, 1983; Dyke et al., 1995; Li et al., 2009; Jia et al., 2014). According to available statistics, the global oil industry endures economic losses caused by lost circulation that run into the hundreds of millions of dollars (Whitfill and Temphill, 2003). With the development of sealing technologies to address small and moderate losses in circulation, methods such as sealing while drilling (Mata and Viega, 2004; Marriott et al., 2005), mud cap sealing (Fossli and Sangesland, 2006; Jayah et al., 2013), chemical gel sealing (Wang et al., 2005; Fernande and Zegarra, 2008), and water drilling (Reyna, 1995; Sweep et al., 2003) have been widely used. However, the performance of these methods is not satisfactory when circulation is lost in the return, and they can actually result in a considerable waste of sealing material and loss of operating time.

Hang's mudding-off technique (Zeng et al., 2005) is an important security measure for maintaining the dynamic balance of pressure inside a well in the event of circulation loss in the return and is widely used in engineering practices. Currently, however, Hang's mudding-off technique is most commonly applied only to "blind Hangs", i.e., when mudding-off cannot reasonably be applied to real leakage loss conditions. Excessively frequent application of Hang's mudding-off technique will consume large amounts of drilling liquid, whereas excessively infrequent application will lead to an overflow. Thus, the well control safety problem is still very prominent. The fundamental reason for this is the lack of a dynamic analysis method that reflects changes in the annulus liquid level in a well shaft.

In this study, a dynamic analysis method was employed to model well shaft leakage loss, based on actual engineering conditions under which Hang's mudding-off technique is used, and models were developed for the effective height of the well shaft annulus liquid level in Hang's mudding-off technique and for the safe operation time after application of Hang's mudding-off technique. The calculation of

* Corresponding author, Pu Liu *. E-mail address: 248161979@qq.com. 
variations in the cross-sectional area of the annulus was also addressed. The reliability of the proposed models was evaluated using calculation examples. The error in the calculated effective liquid level height was $1.22 \%$ when dynamic leakage loss was considered, and the error in the safe operation time calculation was $3.58 \%$. These results illustrate the accuracy of the models. The analysis method proposed in this paper can be used to solve problems related to calculation of the engineering parameters involved in Hang's mudding-off technique and averting the risks of well control safety under conditions of circulation loss in the return, thereby optimising Hang's mudding-off technique and reducing project costs.

\section{Model for effective height of well shaft annulus liquid level in Hang's mudding-off technique}

\subsection{Physical model of height change in well shaft annulus liquid level}

In the event of a circulation loss in the return, it is assumed that the leakage loss flow of the well shaft drilling liquid is $\mathrm{Q}$ and that the amount of Hang's mudding-off drilling liquid is $\mathrm{q}$. If $\mathrm{Q}=\mathrm{q}$, the drilling liquid height in the well shaft remains unchanged; if $\mathrm{Q}>\mathrm{q}$, the drilling liquid height in the well shaft continues to increase; and if $\mathrm{Q}<\mathrm{q}$, the drilling liquid height in the well shaft continues to decrease. When $\mathrm{Q}$ $<\mathrm{q}$, after priming with a certain amount of drilling liquid, the drilling liquid height in the well shaft changes from $\mathrm{H}_{2}$ to $\mathrm{H}_{1}$, as shown in Fig. 1 .

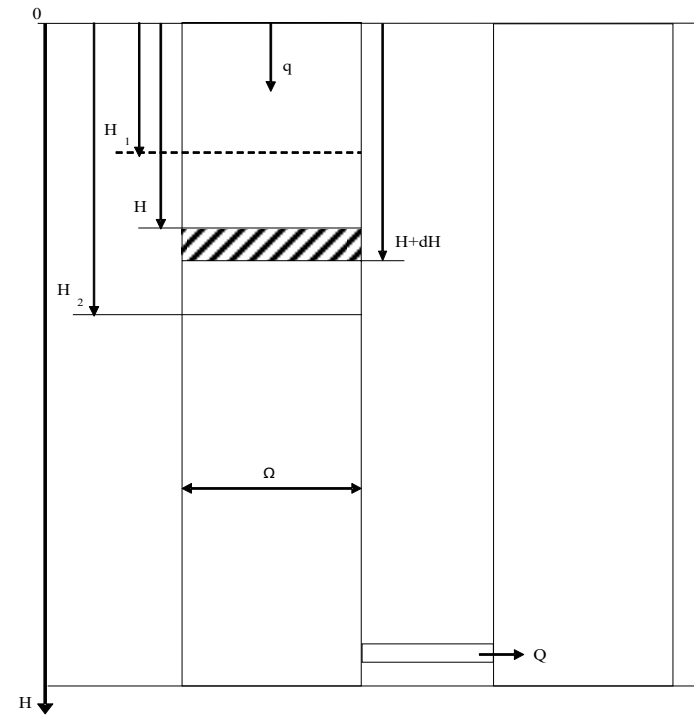

Fig. 1. Physical model of height change in well shaft annulus liquid level in Hang's mudding-off technique

\subsection{Model for effective height of well shaft annulus liquid level}

Considering the micro time unit $d t$ and assuming that the amount of Hang's mudding-off drilling liquid is q, the amount of Hang's mudding-off drilling liquid is calculated as follows:

$$
d V_{1}=q d t
$$

where $V_{l}$ is the amount of Hang's mudding-off liquid in $\mathrm{m}^{3}$ and $q$ is the priming rate in $\mathrm{m}^{3} / \mathrm{h}$.

Given the leakage loss flow amount Q of the well shaft drilling liquid, the leakage loss amount of the drilling liquid in $d t$ is calculated as follows:

$$
d V_{2}=Q d t
$$

where $V_{2}$ is the leakage loss during the quantitative priming in $\mathrm{m}^{3}$ and Q is the leakage loss rate in $\mathrm{m}^{3} / \mathrm{h}$.

Given the cross-sectional area $\Omega$ of the well shaft, the volume change of the well shaft annulus drilling liquid in $d t$ is calculated as follows:

$$
d V=d V_{1}-d V_{2}=\Omega d H
$$

where $V$ is the volume in $\mathrm{m}^{3}$ and $\Omega$ is the annular cross-sectional area of the well shaft in $\mathrm{m}^{2}$.

Based on Eqs. (1), (2), and (3), we have:

$$
d H=\frac{(q-Q) d t}{\Omega}
$$

After Hang's muddling-off during period $T_{2-1}$, the height of the well shaft annulus liquid level changes from $H_{2}$ to $H_{1}$, i.e., the effective liquid level height (the expected height of Hang's mudding-off) $H_{2-1}$ is calculated as follows:

$$
H_{2-1}=\int_{H_{2}}^{H_{1}} d H=\int_{0}^{T_{2-1}} \frac{(q-Q)}{\Omega} d t
$$

In engineering practice, to apply Hang's mudding-off technique to specific drilling rigs and well structures, the flow amount, $q$, of the drilling liquid for Hang's mudding-off technique and the cross-sectional area $\Omega$ of the well shaft are assumed to be constant, while the leakage loss flow rate $Q$ of well shaft drilling liquid is variable and is related to the pressure difference with the bottom of the well. Various mathematical models for the leakage loss amount $Q$ (linear functions, quadratic functions, and exponential functions with respect to the height of the annulus liquid level) and the effective liquid level height $H_{2-1}$ are listed in Table 1. 
Table 1 Mathematical models for leakage loss rate and effective height

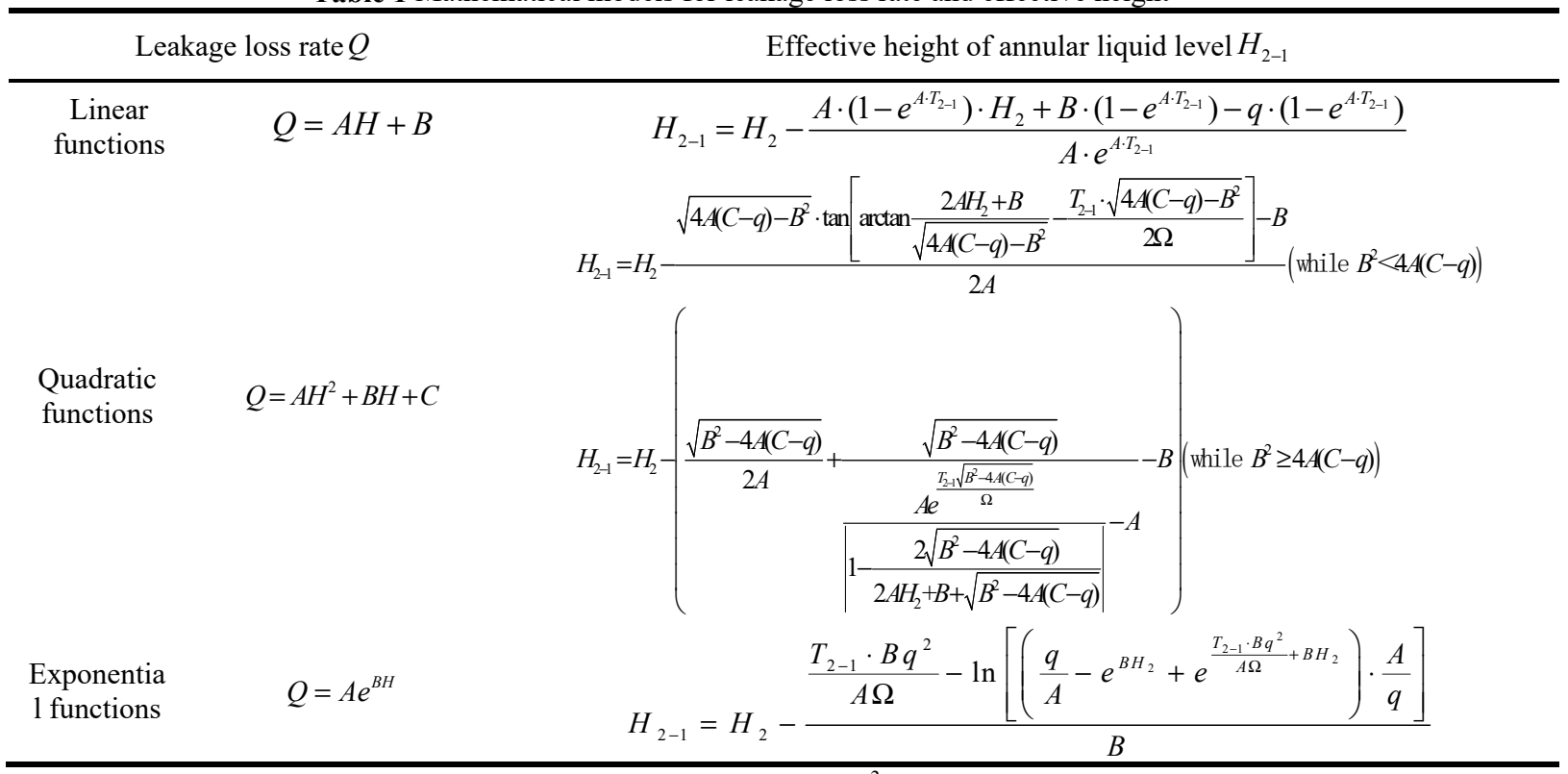

In Table $1, A, B$ and $C$ are constants; $T_{2-1}$ is the time required to prime the drilling fluid in hours; $H_{2}$ is the critical liquid level depth in meters; $H_{1}$ is the liquid level depth in meters after Hang's mudding-off; and $H_{2-1}$ is the effective height of the drilling liquid level in meters.

\subsection{Calculation examples}

Consider an example in which the diameter of the well hole is $215.9 \mathrm{~mm}$ and the length of the drilling pipe is $127 \mathrm{~mm}$. Circulation loss in the return occurs at a well depth of $4500 \mathrm{~m}$. The depth of the well shaft annulus liquid level is $300 \mathrm{~m}$. The leakage loss rate is assumed to be defined by the following quadratic function:

$$
Q=-3.406 \times 10^{-6} H^{2}-0.01144 H+6.22178
$$

where $\mathrm{H}$ is the liquid level in the well.

Hang's mudding-off technique is applied. The density of the drilling liquid is $1.92 \mathrm{~g} / \mathrm{cm}^{3}$, the displacement is $10 \mathrm{~L} / \mathrm{s}$, and Hang's time is $4.38 \mathrm{~min}$. The effective height of the well shaft annulus liquid level is found to be $101.57 \mathrm{~m}$ using a liquid level meter after Hang's mudding-off.

Without considering the leakage, the effective height of the liquid level is calculated as follows:

$$
H_{2-1}=\frac{q \cdot T_{2-1}}{\Omega}
$$

where $\Omega=0.0239 \mathrm{~m}^{2}, T_{2-1}=0.073 \mathrm{~h}$, and $q=36$

As Table 2 shows, the error in the effective liquid level height was $1.22 \%$ with leakage considered and $8.26 \%$ without leakage considered. These results show that the model for the effective height of the well shaft annulus liquid level has good calculation accuracy. $\mathrm{m}^{3} / \mathrm{h}$.Substituting the above into Eq. (7) yields the following:

$$
H_{2-1}=\frac{36 \times 0.073}{0.0239}=109.96 \mathrm{~m}
$$

Considering the leakage, the effective height of the liquid level is calculated as follows:

$$
H_{2-1}=H_{2}-\frac{\sqrt{4 A(C-q)-B^{2}} \cdot \tan \left[\arctan \frac{2 A H_{2}+B}{\sqrt{4 A(C-q)-B^{2}}}-\frac{T_{2-1} \cdot \sqrt{4 A(C-q)-B^{2}}}{2 \Omega}\right]-B}{2 A}
$$

where $A=-3.406 \times 10^{-6}, B=-0.01144, C=6.22178$, and $H_{2}=300 \mathrm{~m}$.

Comparison and analysis

A comparison of the results for the effective height of the well shaft annulus liquid level is shown in Table 2.

Table 2 Comparison of results of effective height of well shaft annulus liquid level

\begin{tabular}{cccc}
\hline & $\begin{array}{c}\text { Effective } \\
\text { height of } \\
\text { liquid level } \\
(\mathrm{m})\end{array}$ & \multicolumn{2}{c}{ Error Analysis } \\
\cline { 3 - 4 } & & $\begin{array}{c}\text { Absolute } \\
\text { error }(\mathrm{m})\end{array}$ & $\begin{array}{c}\text { Relative } \\
\text { error }(\%)\end{array}$ \\
\hline $\begin{array}{c}\text { Without } \\
\text { considering } \\
\text { leakage }\end{array}$ & 109.96 & 8.39 & 8.26 \\
$\begin{array}{c}\text { Considering } \\
\text { leakage } \\
\text { Measured } \\
\text { value }\end{array}$ & 100.33 & 1.24 & 1.22 \\
\hline
\end{tabular}

\section{Model for safe operation time after Hang's mudding-off}

\subsection{Model for safe operation time}

After the application of Hang's mudding-off (injection rate $q=0)$ because of continued leakage $(\mathrm{Q}<0)$, the liquid level changes from $H_{1}$ to $H_{2}$. The corresponding time $T_{1-2}$ is considered the "safe operation time" (during which there is no safety issue): 


$$
T_{1-2}=\int_{0}^{T_{1-2}} d t=\int_{H_{1}}^{H_{2}} \frac{\Omega}{Q} d H
$$

liquid level height $H$, the integration results for the safe operation time are as shown in Table 3.

When the leakage loss rate $Q$ is a function of the

Table 3 Integration results for leakage loss rate $Q$ and safe operation time $T_{1-2}$

\begin{tabular}{lcc}
\hline \multicolumn{2}{c}{ Leakage loss rate $Q$} & Safe operation time $T$ \\
\hline $\begin{array}{c}\text { Linear } \\
\text { function }\end{array}$ & $Q=A H+B$ & $T_{1-2}=\frac{\Omega}{A} \ln \frac{A H_{2}+B}{A H_{1}+B}$ \\
$\begin{array}{l}\text { Quadratic } \\
\text { function }\end{array}$ & $Q=A H^{2}+B H+C$ & $T_{1-2}=\frac{2 \Omega}{\sqrt{4 A C-B^{2}}}\left[\arctan \frac{2 A H_{2}+B}{\sqrt{4 A C-B^{2}}}-\arctan \frac{2 A H_{1}+B}{\sqrt{4 A C-B^{2}}}\right]\left(\right.$ while $\left.B^{2}<4 A C\right)$ \\
$\begin{array}{l}\text { Exponenti } \\
\text { al function }\end{array}$ & $Q=A e^{B H}$ & $\Omega$ \\
\hline
\end{tabular}

\subsection{Calculation examples}

The calculation conditions are as described in Section 2.3. After Hang's mudding-off, the measured liquid level depth is $198.43 \mathrm{~m}$. Using a liquid level meter, the liquid level depth is found to have fallen to $300 \mathrm{~m}$ after $48 \mathrm{~min}$. The safe operation time can thus be calculated.

The model for the safe operation time $T_{1-2}$ can be expressed as a quadratic function $\left(B^{2} \geq 4 A C\right)$ :

$T_{1-2}=\frac{\Omega}{\sqrt{B^{2}-4 A C}}\left[\ln \left|\left[\frac{\left.2 A H_{2}+B-\sqrt{B^{2}-4 A C}\right]}{\left[2 A H_{2}+B+\sqrt{B^{2}-4 A C}\right]}\right]-\ln \right|\left[\frac{\left.2 A H_{1}+B-\sqrt{B^{2}-4 A C}\right] \mid}{\left[2 A H_{1}+B+\sqrt{B^{2}-4 A C}\right]}\right] \mid\right.$

where $H_{1}=198.43 \mathrm{~m}$ and $H_{2}=300 \mathrm{~m}$.

The results of the calculations were compared with the measured values. The relative error of the safe operation time was $3.58 \%$, based on the measured value, which demonstrates that the proposed model for the safe operation time provides a high level of accuracy.

\section{Calculation of the cross-sectional areas of the annulus}

\subsection{Physical model of the cross-sectional areas of the annulus}

In engineering practice, the cross-sectional area of the annulus $\Omega$ at the effective height of the liquid level is not constant because of the well structure, as shown in Fig. 2.

The cross-sectional area of the annulus $\Omega$ typically varies with the inner diameter of the casing pipe and the outer diameter of drilling tool, which may be related in the following ways: (1) same inner diameter of the casing pipe and outer diameter of the drilling tool, as shown in Fig.3(a); (2) same inner diameter of the casing pipe but different outer diameter of the drilling tool, as shown in Fig. 3(b); (3) different inner diameter of the casing pipe but same diameter of the drilling tool, as shown in Fig. 3(c); or (4) different inner diameter of the casing pipe and outer diameter of the drilling tool, as shown in Fig. 3(d).

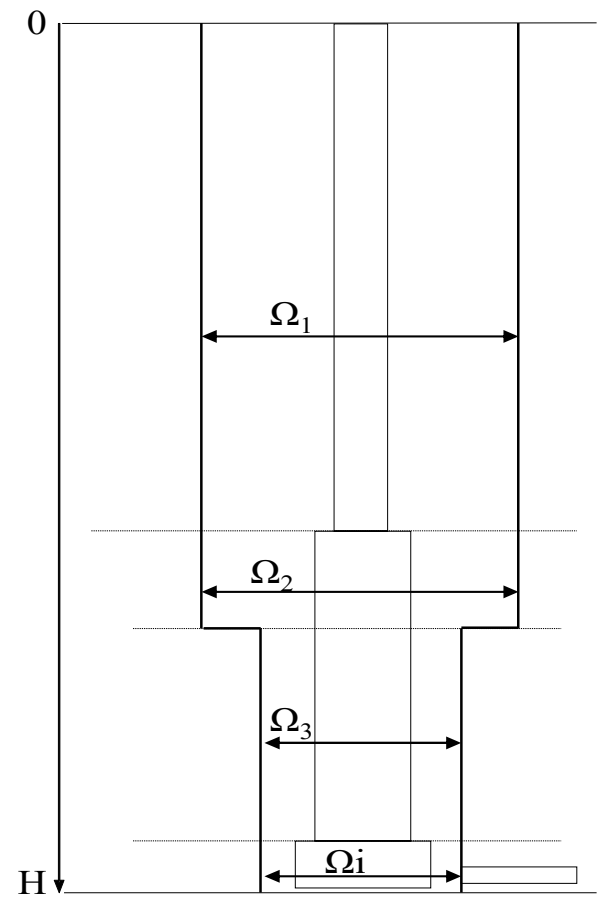

Fig. 2 Cross-sectional areas of the annulus 


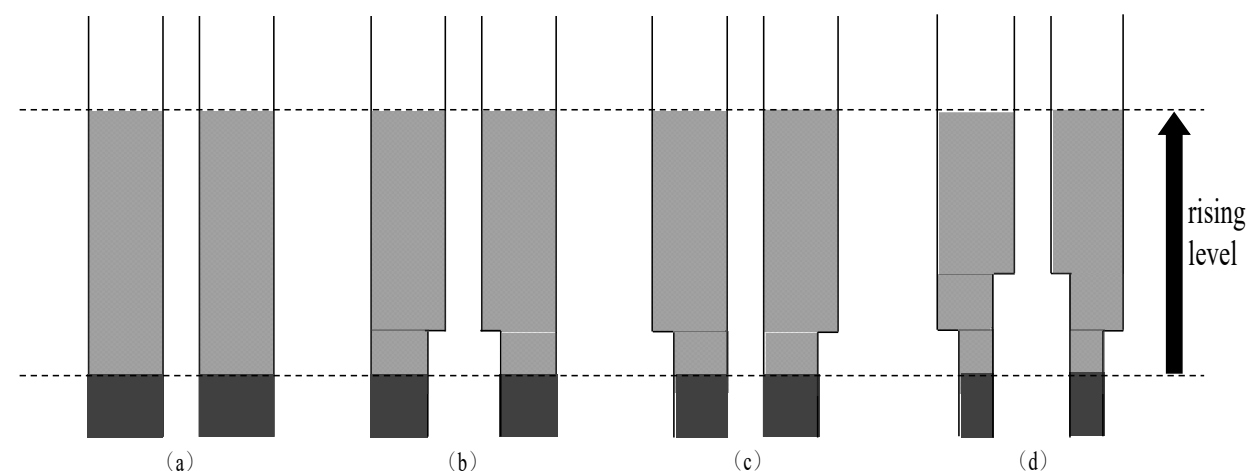

Fig. 3 Liquid level height variations of different cross-sectional areas of the annulus

The cross-sectional area of the annulus can be expressed as a piecewise function, based on the combination of the well structure and the drilling tool. Therefore, the effective liquid level height $H_{2-1}$ and the safe operation time $T_{1-2}$ should be obtained by piecewise calculation and superposition:

$$
\begin{gathered}
H_{2-1}=\sum_{i=1}^{n}\left(H_{2-1}\right)_{i} \\
T_{1-2}=\sum_{i=1}^{n}\left(T_{1-2}\right)_{i}
\end{gathered}
$$

where $i$ and $n$ are the piecewise number and number of pieces, respectively.

\subsection{Calculation examples}

The calculation conditions are as described in Section 2.3. The pipe inner diameter and drilling tool outer diameter are shown in Fig. 4.

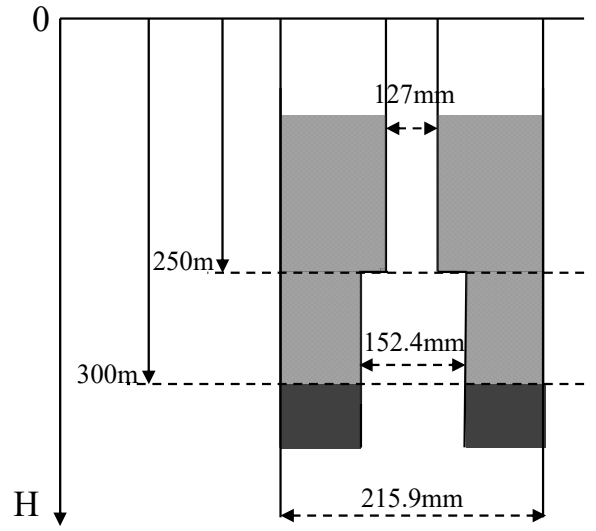

As shown in Fig. 4, the number of pieces in this example is $n=2$. The cross-sectional area of the first annulus $(\mathrm{i}=1)$ is $0.0239 \mathrm{~m}^{2}$ (for a pipe inner diameter of $215.9 \mathrm{~mm}$ and a drilling tool outer diameter of 127 $\mathrm{mm})$, and the cross-sectional area of the second annulus $(\mathrm{i}=2)$ is $0.0184 \mathrm{~m}$ (for a pipe inner diameter of $215.9 \mathrm{~mm}$ and a drilling tool outer diameter of 152.4 $\mathrm{mm}$ ). The segment point is located $250 \mathrm{~m}$ from the wellhead.

Taking the analysis of the change in the effective liquid level height as an example, the change in the cross-sectional area of the annulus is determined as follows:

a. First annulus $(i=1)$

Based on the change in the cross-sectional area of the annulus, the effective height of the liquid level after 2.72 minutes of Hang's mudding-off for the first annulus $(\mathrm{i}=1)$ increased by $61.55 \mathrm{~m}$.

b. Second annulus $(i=2)$

Based on the change in the cross-sectional area of the annulus, the effective height of the liquid level after 1.66 minutes of Hang's mudding-off for the second annulus $(i=2)$ increased by $50 \mathrm{~m}$.

c. Total effective height of liquid level

Therefore, the effective height of the liquid level increased by $111.55 \mathrm{~m}$. The influence of the change in the cross-sectional area on the control of Hang's mudding-off is summarized in Table 4.

Fig. 4 Pipe inner diameter and drilling tool outer diameter

\begin{tabular}{|c|c|c|c|c|c|c|c|c|}
\hline \multicolumn{2}{|c|}{$\begin{array}{l}\text { Calculation length } \\
(\mathrm{m})\end{array}$} & \multirow{2}{*}{$\begin{array}{l}\text { Cross-sect } \\
\text { ional area } \\
\quad\left(\mathrm{m}^{2}\right)\end{array}$} & \multirow{2}{*}{$\begin{array}{c}\text { Displace } \\
\text { ment } \\
(\mathrm{L} / \mathrm{s})\end{array}$} & \multirow{2}{*}{$\begin{array}{l}\text { Hang' } \\
\text { s time } \\
(\text { min } \\
\text { ) }\end{array}$} & \multicolumn{2}{|c|}{$\begin{array}{l}\text { Effective height } \\
(\mathrm{m})\end{array}$} & \multicolumn{2}{|c|}{ Error analysis } \\
\hline $\begin{array}{l}\text { Total } \\
\text { depth }\end{array}$ & $\begin{array}{l}\text { Segment } \\
\text { length }\end{array}$ & & & & $\begin{array}{l}\text { Segment } \\
\text { length }\end{array}$ & $\begin{array}{l}\text { Total } \\
\text { length }\end{array}$ & $\begin{array}{l}\text { Absolute } \\
\text { error }(m)\end{array}$ & Relative error $(\%)$ \\
\hline \multirow{5}{*}{300} & 300 & 0.0239 & \multirow{5}{*}{10} & \multirow{5}{*}{4.38} & 100.33 & $\begin{array}{c}100.3 \\
3\end{array}$ & 12.31 & 10.93 \\
\hline & 250 & 0.0239 & & & 61.55 & \multirow{2}{*}{$\begin{array}{c}111.5 \\
5\end{array}$} & \multirow[b]{2}{*}{1.09} & \multirow[b]{2}{*}{0.98} \\
\hline & 50 & 0.0184 & & & 50 & & & \\
\hline & 250 & 0.0239 & & & 62.64 & \multirow{2}{*}{$\begin{array}{c}112.6 \\
4\end{array}$} & 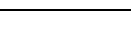 & \multirow{2}{*}{ - } \\
\hline & 50 & 0.0184 & & & 50 & & - & \\
\hline
\end{tabular}

Table 4 Influence of change in cross-sectional area on effective height of the liquid level in the well 
A comparison of the values listed in Table 5 with the measured values reveals a relative error of $0.98 \%$ when the change in the cross-sectional area of the annulus is considered or $10.93 \%$ when the cross-sectional area of the annulus is not considered. This example demonstrates that the models for determining the effective height of the well shaft annulus and the safe operation time can be effectively solved by piecewise calculation and superposition under the conditions of annulus cross-sectional area change.

\section{Conclusions}

A dynamic analysis method was developed in this study for calculating well shaft leakage loss and thereby determining the required values of engineering parameters associated with Hang's mudding-off technique. This solution method has considerable potential for lessening the risks associated with well control safety under the conditions of circulation loss in return, optimisation of Hang's mudding-off technique, and reduction of project costs.

A model was developed for use in determining the effective height of the well shaft annulus liquid level during Hang's mudding-off process. The error in the effective liquid level height was found to be $1.22 \%$ when the dynamic leakage loss was considered, which demonstrates that the mathematical model for determining the effective height of the well shaft annulus liquid level offers a high level of accuracy.

A model was developed to determine the safe operation time after application of Hang's mudding-off technique. Based on comparison with measured values, the error in the calculated safe operation time was found to be $3.58 \%$, which demonstrates that the model for determining the safe operation time offers a high level of accuracy.

The models for determining the effective height of the well shaft annulus and the safe operation time can be solved by piecewise calculation and superposition under the conditions of change in the cross-sectional area of the annulus.

\section{Acknowledgment}

This study is supported by ChongQing Land resources and Housing Management Bureau Science and Technology Planning Project(CQGT-KJ-2014037), Chinese National Natural Science Foundation (41502287), Chongqing City Social Undertakings and Livelihood Protection Science and Technology Innovation Special Project (cstc2017shmsA120001, cstc2018jscx-mszdX0074), Open Fund of Key Laboratory of Mine Geological Hazards, Mechanism and Prevention (2018-08), Fuling District technology project (FLKJ2018BBA3065, FLKJ2018BBA3066). We gratefully acknowledge the financial support received. In addition, the authors would like to thank Professor H. Liu at the Southwest Petroleum University for his constructive suggestions.

\section{References}

1. Dyke CG, Wu B, Milton-Tayler D, 1995. Advances in characterizing natural fracture permeability from mud-log data $[\mathrm{J}]$. SPE Formation Evaluation, 10(3): 160-166.

2. Fernande ZLC, Zegarra H, 2008. Characterization and surfactant-enhanced washing treatability of drilling fluids stored for more than 20 years [J], Journal of Surfactants and Detergents (11): 307-314.

3. Fossli B, Sangesland S, 2006. Controlled mud-cap drilling for subsea applications: well-control challenges in deep waters [J], SPE Drilling \& Completion, 21(02):133-140.

4. Jayah, M, Noreffendy, Aziz A, Intan A, Travis, F, Voshall, A, 2013. Implementation of PMCD to explore carbonate reservoirs from semi-submersible rigs in Malaysia results in safe and economical drilling operations [R]. SPE/IADC-163479-MS.

5. Jia L, Chen M, Hou B, 2014. Drilling fluid loss model and loss dynamic behavior in fractured formations $[\mathrm{J}]$. Petroleum Exploration and Development, 41(1): 95-101.

6. Li L, Liu H, Li F, 2009. Research on safe tripping and electrical measurement support techniques under the condition of sensitive loss circulation loss to return $[\mathrm{J}]$. West-china Exploration Engineering, 21(6): 66-68.

7. Lin A, 1983. Application of "maintaining low differential pressure" method in well completion and fluid loss control $[\mathrm{J}]$. Natural Gas Industry, 3(1): 31-33.

8. Marriott T, Griffith J, Szutiak G, 2005. Foamed conventional lightweight cement slurry for ultra-low density and low ECDs solves loss-circulation problem across coal formations: a case history [R]. SPE96108.

9. Mata F, Veiga M, 2004. Cross linked cements solve lost circulation problems [R]. SPE90496.

10. Reyna E, 1995. Case history of floating mud cap drilling techniques: Ardalin Field, Timan Pechoran Basin, Russia [C]. SPE 29423.

11. Sweep MN, Bailey JM, Stone CR, 2003. Closed-hole circulation drilling: Case study of drilling a high-pressure fractured reservoir-Tengiz Field, Tengiz, Republic of Kazakhstan [C]. SPE/IADC 79850.

12. Wang J, Li Y, Li Q, 2005. Evaluation of sealing ability of new multi-function composite gel [J]. Natural Gas Industry, 25(9): 101-103.

13. Whitfill DL, Hemphill T, 2003. All lost-circulation materials and systems are not created equal [C]. SPE 84319.

14. Zeng M, Zeng S, Mao J, 2005. Treating techniques of blowout lost circulation coexistence in gas hole drilling [J]. Natural Gas Industry, 25(6): 42-44. 